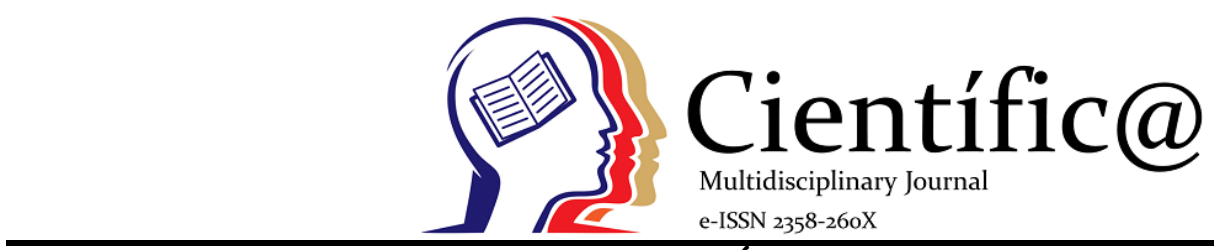

\title{
ESTUDO FITOQUIMICO, ENZIMÁTICO E CAPACIDADE ANTIOXIDANTE DA POLPA DE BACABA (OENOCARPUS BACABA MART) PARAENSE
}

\author{
PHYTOCHEMICAL, ENZYMATIC AND ANTIOXIDANT CAPACITY OF BACABA PULP \\ (OENOCARPUS BACABA MART)
}

Adilson Ferreira Santos Filho ${ }^{1 *}$; Maricely Uría Toro ${ }^{1}$; Iuri Costa Ferreira ${ }^{1}$

${ }^{1}$ Universidade Estadual do Pará - Brazil - adilsonferreirasf@gmail.com*

\section{Info}

Recebido: 06/2020

Publicado: $12 / 2020$

DOI: $10.29247 / 2358-260 X .2020 v 7 i 2.4558$

ISSN: 2358-260X

Palavras-Chave
Atividade enzimática, Purificação parcial,
Bioativos
Keywords:

Enzymatic activity, Partial purification, Bioactive

\begin{abstract}
Oenocarpus Bacaba Mart. it is a fruit very appreciated by several consumers of the most different age groups, being a fruit that can present several popular names like bacaba, bacaba-açu or bacaba-real. Bacaba is a palm tree native to the Amazon region, which can be an interesting source of substances. The objective of the present work was to study the pulp of the bacaba from Pará, targeting the presence of phytochemical constituents, physical-chemical characterization, determination of the enzymatic activity of peroxidase (POD) and polyphenoloxidase (PPO), separation of them by molecular exclusion chromatography and the determination of antioxidant capacity by the methods of DPPH, CUPRAC, FRAP and ABTs. In this work it was possible to partially purify the
\end{abstract} peroxidase (POD) and polyphenol oxidase (POP) enzymes from the bacaba pulp (Oenocarpus Bacaba Mart) using the Sephadex G-50. It was observed that it presented a purification factor of 1.10 for PPO and 4.58 for POD. It was found the optimal activity of these enzymes in relation to the $\mathrm{pH}$, temperature and concentration of the extractive solution. By means of the enzymatic kinetics were found $\mathrm{Km}$ of $6.7 \times 10-6 \mathrm{M}$ for POD and 2.1x10-5 M for PPO. It was found presence of Phenols, anthocyanins, anthocyanidins, chalconas, aurones, flavones, flavonols, xanthones, leucoantocianidins, saponins, pentacyclic triterpenes. Total flavonoids and phenolics were quantified, being $16.41 \mathrm{mg}$ quercitin $100 \mathrm{~g}-1$ and $98 \mathrm{mg}$ gallic acid $100 \mathrm{~g}-1$. It was verified that the bacaba pulp has antioxidant ability measured by the DPPH, FRAP, CUPRAC and ABTs methods.

\section{Resumo}

A Oenocarpus Bacaba Mart. é um fruto muito apreciado por diversos consumidores das mais diferentes faixas etárias, sendo um fruto que pode apresentar diversos nomes populares como bacaba, bacaba-açu ou bacaba-verdadeira. A bacaba é uma palmeira nativa da região Amazônia, a qual pode ser uma fonte interessante de nutrientes. 0 objetivo do presente trabalho foi o estudo da polpa da bacaba paraense tendo como alvo a presença de constituintes fitoquímicos, caracterização físico-química, determinação da atividade enzimática da peroxidase (POD) e polifenoloxidase (PPO), separação das mesmas por cromatografia de exclusão molecular e determinação da capacidade antioxidante pelos métodos de DPPH, CUPRAC, FRAP e ABTs. Neste trabalho foi possível purificar parcialmente as enzimas peroxidase (POD) e polifenoloxidase (POP) da polpa de bacaba (Oenocarpus Bacaba Mart.) utilizando o Sephadex G-50. Observou-se que apresentou um fator de purificação de 1,10 para a PPO e de 4,58 para a POD. Foi encontrada a atividade ótima dessas enzimas em relação ao pH, temperatura e concentração da solução extrativa. Por meio da cinética enzimática foram encontrados Km de 6,7x10-6M para POD e 2,1x10-5M para PPO. Foi encontrada presença de fenóis, antocianinas, antocianidinas, chalconas, auronas, flavonas, flavonóis, xantonas, leucoantocianidinas, saponinas, triterpenos pentacíclicos. Os flavonóides totais e fenólicos foram quantificados, sendo 16,41 mg de quercetina 100.g-1 e $98 \mathrm{mg}$ de ácido gálico.100g-1. Verificou-se que a polpa de bacaba possui capacidade antioxidante medida pelos métodos DPPH, FRAP, CUPRAC e ABTs 


\section{INTRODUÇÃO}

A região amazônica possui diversas variedades de frutas que eram desconhecidas, porém estão ganhando cada vez mais espaço nas mais diversas áreas de pesquisa, pois apresentam relevância devido ao excelente sabor, características nutricionais e atividade antioxidante. Dentre a vasta diversidade da região amazônica pode-se destacar a bacaba (Oenocarpus Bacaba Mart.), a qual possui frutos em cachos, de coloração negro-violácea, com polpa mucilaginosa de alto teor de lipídios, a qual é característica das regiões do Pará e Amazonas, em áreas de solos pobres, argilosos e não alagados (EISERHARDT et al., 2011; CARNEIRO et al., 2013; NERI-NUMA et al., 2018).

O fruto é consumido in natura, apresentando a polpa cor creme leitoso de sabor agradável. Este fruto possui alto valor comercial para fins agroindustriais sendo bastante utilizado na produção de sucos, sorvetes, doces e outros produtos, além de ser uma fonte com grande potencial a ser estudado (ABADIO FINCO et al., 2012; ABADIO FINCO et al.,2013).

$\mathrm{Na}$ medicina popular, as propriedades funcionais dos frutos de bacaba, bem como os benefícios decorrentes da ingestão desta matéria prima, ainda não foram suficientemente estudado e esclarecido (ABADIO FINCO et al., 2016; NASCIMENTO et al., 2019). Contudo a literatura apresenta algumas pesquisas realizadas que alegam algumas propriedades relacionadas a ingestão do fruto, como ação antioxidante (LEBA et al., 2016) e potencial na atividade contra a carcinogênese (ABADIO FINCO et al., 2016), porém ainda não se tem muitos estudos acerca do conteúdo da bacaba paraense.

Desta forma, o objetivo do presente trabalho foi o estudo da polpa da bacaba paraense tendo como alvo a presença de constituintes fitoquímicos, caracterização físico-química, determinação da atividade enzimática da peroxidase (POD) e polifenoloxidase (PPO), separação das mesmas por cromatografia de exclusão molecular e a determinação capacidade antioxidante pelos métodos de DPPH, CUPRAC, FRAP e ABTs.

\section{MATERIAIS E MÉTODOS}

\section{Reagentes}

Os padrões foram obtidos da Sigma Chemical Co. (St. Louis, EUA) e os solventes utilizados foram de grau analítico da Merck.

\section{Matéria - prima}

As amostras de polpa de bacaba (Oenocarpus Bacaba Mart.) foram obtidas no município de Cametá no Estado do Pará, sendo congelados $-18{ }^{\circ} \mathrm{C}$ e transportados para as análises no Laboratório de Química da Universidade do Estado do Pará.

\section{Presença de fitonutrientes}

As análises fitoquímicas seguiram os procedimentos descritos por Matos (1997) e Ugochukwu, Uche e Ifeanyi (2013).

Pesou-se cerca de 20 gramas de polpa e adicionou-se $60 \mathrm{~mL}$ de etanol a 30\% para realizar a extração dos compostos, servindo de extrato para determinar a presença ou ausência das substancias abaixo:

Teste de Fenóis e Taninos: utilizou-se $3 \mathrm{~mL}$ do extrato com 3 gotas da solução de $\mathrm{FeCl}_{3}$ a $10 \%$, a formação da cor azul com precipitado, indica a presença destes compostos.

Teste de antocianidinas, antocianinas e flavonoides: utilizou-se $3 \mathrm{~mL}$ do extrato em 3 tubos diferentes, em seguida variou o $\mathrm{pH}$ de cada tubo com a amostra para os pHs 3, 8.5 e 11 onde a mudança de coloração nos tubos, indica a presença destes compostos.

Teste de leucoantocianidinas, catequinas e flavanonas: utilizaram-se os tubos do teste anterior, 
sendo aquecidos por 3 minutos, onde a mudança ou intensificação da coloração indica a presença destes compostos.

Teste de esteroides e triterpenos pentaciclicos: utilizou-se $3 \mathrm{~mL}$ do extrato em um becker e adicionouse clorofórmio. Em seguida foi colocado $1 \mathrm{~mL}$ de anidrido acético e três gotas de $\mathrm{H}_{2} \mathrm{SO}_{4}$, onde a coloração vermelha indica a presença de esteroide ou coloração verde para triterpenos pentaciclicos.

Teste de saponinas: retirou-se $3 \mathrm{~mL}$ do extrato e adicionou-se $10 \mathrm{~mL}$ de água destilada e agitou-se por 3 minutos onde a presença de espuma, indica a presença deste composto.

Teste de cumarinas: Se adicionou 2 gotas de extrato em um papel de filtro. Aplicou-se sobre uma das manchas uma gota de $\mathrm{KOH}$ (1 M), em seguida cobriuse parcialmente uma das manchas com carvão ativado e levou-se o papel para exposição à lâmpada UV por três minutos, onde o aparecimento de uma fluorescência indica a presença deste composto.

Teste de alcaloides: pegou-se $3 \mathrm{~mL}$ e adicionou $\mathrm{NaOH}$ até alcançar o pH 11 e realizou-se uma extração com éter e clorofórmio (3:1), em seguida adicionou-se porções de $\mathrm{HCl}(0,1 \mathrm{M})$. Por fim, colocaram-se três gotas do reagente de Dragendorff, onde a presença de um precipitado indica a presença deste composto.

\section{Caracterização físico-química}

A acidez total foi mensurada conforme a metodologia do Instituto Adolf Lutz (2008). Tendo resultados expressos em porcentagem (\%) de ácido cítrico.

Quantificou-se o teor de umidade segundo o método gravimétrico da AOAC (2005), aplicando uma temperatura de $70^{\circ} \mathrm{C}$ na polpa.

O teor de lipídeos foi realizado conforme o método da AOAC (2005), que está baseado na extração intermitente com solvente orgânico. O solvente orgânico utilizado foi o éter de petróleo.

Realizou-se análise de proteínas pelo método de micro Kjeldahl, segundo a metodologia da AOAC (2005), que consiste na digestão, destilação e titulação da amostra. Os equipamentos para efetuar o método foram: digestor da marca TECNAL, modelo TE-007A e destilador de nitrogênio TECNAL modelo TE$036 / 1$.

O teor de cinzas foi determinado pela metodologia do Instituto Adolfo Lutz (2008).

Para a quantificação dos açúcares totais e redutores foi utilizada a metodologia de ácido 3,5 dinitrossalicílico (DNS) conforme descrito por Maldonade, Amaya \& Scamparini (2008), sendo analisados em espectrofotômetro (Femto 700) a 540 nm. A quantidade de açúcares foi medida por meio de uma curva de calibração da glicose $(\mathrm{y}=4,9579 \mathrm{x}+$ 0,$\left.128 ; R^{2}=0,9990\right)$. Os teores dos não redutores foram encontrados pela diferença dos totais com os redutores.

\section{Compostos bioativos}

Quantificou-se o teor de fenólicos totais conforme o método espectrofotométrico descrito por Singleton, Orthofer \& Lamuela (1999) e modificado por Georgé et al. (2005), onde o extrato foi elaborado a partir de cinco gramas da amostra, com uma solução de acetona a 70\% sob agitação por 30 minutos, após a agitação centrifugou-se o extrato e utilizou-se o sobrenadante para a análise. A absorbância foi lida em $750 \mathrm{~nm}$ com um espectrofotômetro uv visível (Femto 700). O conteúdo de fenóis totais foi determinado por meio de uma curva padrão de ácido gálico $\left(y=0,0107 x+0,0491 ; R^{2}=0,9962\right)$. A partir da reta obtida, realizou-se o cálculo do teor de fenólicos totais, expresso em mg de ácido gálico.100 g-1.

$\mathrm{O}$ teor de flavonoides totais seguiu a metodologia descrita na literatura (MEDA et al, 2005; 
AHN et al., 2007) onde o extrato foi elaborado com 10 gramas de amostra, sobre agitação com uma solução de metanol 50\% e acetona $80 \%$ (1:1), por 30 minutos, em seguida centrifugou-se o extrato e utilizou-se o sobrenadante para reagir com a solução de cloreto de alumínio a 2\%. A absorbância foi lida com o auxílio de espectrofotômetro em um comprimento de onda de $415 \mathrm{~nm}$, após 10 minutos de reação, utilizando o metanol como branco. Uma curva padrão de quercetina $\left(y=0,0206 x+0,0038 ; R^{2}=0,9942\right)$ foi utilizada, para determinação do teor de flavonoides totais na amostra, sendo expresso em mg de quercetina. $100 \mathrm{~g}^{-1}$ de amostra.

\section{Determinação da atividade antioxidante}

Para a elaboração dos extratos antioxidantes da polpa de bacaba, pesou-se cerca de 5 gramas da amostra, onde adicionou-se $20 \mathrm{~mL}$ de metanol a $50 \%$, homogeneizou-se e manteve a mistura em agitação por 60 minutos. Após esse tempo foi realizada a centrifugação. O sobrenadante foi transferido para um balão volumétrico de $50 \mathrm{~mL}$. No resíduo da primeira extração foi acrescentado $20 \mathrm{~mL}$ de acetona a $70 \%$, repetindo o mesmo processo de extração do metanol. O novo sobrenadante foi adicionado junto com o primeiro, aferindo-se o balão com água destilada, até completar o volume final. Este extrato serviu para realizar as análises de ABTS, DPPH, FRAP e CUPRAC.

A atividade antioxidante determinada pelo método ABTS foi segundo Kuskoski et al. (2004), onde o ABTS reage estequiometricamente a uma relação 1:0,5 com o perssulfato de potássio. Foram transferidos $0,03 \mathrm{~mL}$ da amostra e $3 \mathrm{~mL}$ da solução de radical ABTS•+ em tubos de ensaio, sendo homogeneizados. Após $7 \mathrm{~min}$, as absorbâncias foram registradas em 754 nm. Utilizou-se uma curva padrão de trolox ( $\mathrm{y}=$ $\left.0,0004 x+0,6307 ; R^{2}=0,9999\right)$, obtendo resultados em $\mu \mathrm{M}$ trolox. $\mathrm{g}^{-1}$.
O método DPPH, idealizado por BrandWilliams et al. (1995), é baseado na captura do radical DPPH (2,2-difenil-1- picril-hidrazil) por antioxidantes, sendo realizadas por um decréscimo do DPPH na absorbância no comprimento de $515 \mathrm{~nm}$, sendo utilizado 3,9 mL de DPPH $(0,06 \mathrm{mM})$ e $0,1 \mathrm{~mL}$ da amostra. Realizou-se uma curva padrão de DPPH, sendo determinado o teor de grama de fruta por grama de $\mathrm{DPPH}^{-1}$.

A atividade antioxidante avaliada quanto ao potencial de redução do Ferro (FRAP), foi realizada segundo Firuzi et al. (2005), onde a solução FRAP foi preparada por adição de $25,0 \mathrm{~mL}$ de tampão acetato 300 $\mathrm{mM}, 2,50 \mathrm{~mL}$ de cloreto férrico hexa-hidratado $20 \mathrm{mM}$ e 2,50 mL de TPTZ (2,4,6-Tris(2-piridil)-s-triazina) 10,0 $\mathrm{mM}$. Foram transferidos $0,09 \mathrm{~mL}$ da amostra em um tubo de ensaio, adicionado $0,27 \mathrm{~mL}$ de água destilada e 2,70 mL de reagente FRAP. Após 30 min de incubação a $37^{\circ} \mathrm{C}$, os dados de absorbância foram registados em $595 \mathrm{~nm}$. Utilizou-se uma curva padrão de sulfato ferroso sendo os resultados expressos em $\mu \mathrm{mol}$ de trolox.g-1.

A metodologia de CUPRAC foi medida segundo Apak et al. (2004), onde utilizou-se $1 \mathrm{~mL}$ de $\mathrm{CuCl}_{2}\left(2 \times 10^{-2} \mathrm{M}\right)+1 \mathrm{~mL}$ de neocuproine $\left(7,5 \times 10^{-3} \mathrm{M}\right)+$ $1 \mathrm{~mL}$ de $\mathrm{NH}_{4} \mathrm{Ac}(1 \mathrm{M})+0,5 \mathrm{~mL}$ de $\mathrm{H}_{2} \mathrm{O}$ e $0,6 \mathrm{~mL}$ do extrato de bacaba, a leitura foi realizada a $450 \mathrm{~nm}$ após 30 minutos de reação. Utilizou-se uma curva padrão de quercetina, os resultados foram expressos em $\mathrm{mg}$ de quercetina.g-1.

\section{Atividade enzimática}

Foram realizados diferentes extratos enzimáticos da polpa de bacaba, onde realizou-se curvas de cinéticas das enzimas polifenoloxidase (PPO) e peroxidase (POD), variando a solução tampão $(50 \mathrm{mM}$ e $100 \mathrm{mM}), \mathrm{pH}(5,5 ; 6,0 ; 6,5 ; 7,0)$, a faixa de concentração do substrato catecol de 25, 50, 75 e 100 
$\mathrm{mM}$ para polifenoloxidase (PPO), enquanto que para peroxidase (POD) foi utilizado o substrato guaiacol a 10, 15, 17,5 e $20 \mathrm{Mm}$, com uma solução de peroxido de hidrogênio na proporção de 1:8 (3 mmol. $\left.\mathrm{L}^{-1}\right) \mathrm{em}$ tampão fosfato, por fim, verificou-se a influência da temperatura $\left(10,20,30,40,50,60,70\right.$ e $\left.80^{\circ} \mathrm{C}\right)$ sobre a atividade das enzimas.

Para a elaboração do extrato enzimático se procedeu da seguinte forma, foi pesado 10 gramas de polpa de bacaba e adicionou-se uma grama de PVP (polivinilpirrolidona) e a solução tampão fosfato para um volume de $50 \mathrm{~mL}$. Em seguida deixou-se em um banho de gelo sobre agitação por uma hora. Por fim, fez-se a separação das fases das amostras na centrifuga a qual se aproveitou o sobrenadante e armazenou em frasco âmbar no congelador a $-18^{\circ} \mathrm{C}$, para ser usadas com fonte enzimática da peroxidase e polifenoloxidase.

Atividade da peroxidase foi determinada pelo método espectrofotométrico, utilizando-se o guaiacol como substrato. Em um tubo contendo $1760 \mu \mathrm{L}$ de solução tampão fosfato, foram adicionados $175 \mu \mathrm{L}$ de guaiacol e $14 \mu \mathrm{L}$ de peróxido de hidrogênio $(3 \mathrm{mmol} . \mathrm{L}$ 1). Após a homogeneização dessa solução, adicionaramse $50 \mu \mathrm{L}$ de extrato enzimático. A cada 30 segundos foi medida de reação formada até a estabilização da atividade enzimática, a absorbância do tetraguaiacol formado foi medida em $470 \mathrm{~nm}$.

A atividade enzimática da polifenoloxidase foi determinada por meio do método espectrofotométrico, onde o meio reacional foi composto por $50 \mu \mathrm{L}$ do extrato enzimático, $250 \mu \mathrm{L}$ de catecol, e $1700 \mu \mathrm{L}$ de solução tampão fosfato de sódio em um tubo. A velocidade da reação foi seguida em $420 \mathrm{~nm}$, com leituras a cada 30 segundos até estabilização da atividade da enzima.

Tanto a atividade da peroxidase quanto a polifenoloxidase foram realizadas segundo Vieira et al. (2003) e Fernandes et al. (2007), onde uma unidade de atividade foi definida como a quantidade de enzima que provoca um aumento na absorbância de 0,001 unidades por minuto.

A quantificação da proteína total nos extratos enzimáticos foi realizada empregando-se a metodologia descrita por Bradford (1976). Em um tubo de ensaio adicionou-se $50 \mu \mathrm{L}$ de amostra, com $50 \mu \mathrm{L}$ de água destilada e $2 \mathrm{~mL}$ do reagente blue (Azul Brilhante de Commassie), após 5 minutos de reação, a absorbância do complexo formado foi medido no espectrofotômetro em $595 \mathrm{~nm}$. Para quantificação das proteínas em mg. $\mathrm{mL}^{-1}$ foi utilizada uma curva padrão de soro albumina $\left(y=32,8 x-0,009 ; R^{2}=0,997\right)$.

A atividade específica da enzima $\left(U \cdot \mathrm{mg}^{-1}\right)$ foi calculada pela razão da atividade enzimática $\left(U \cdot \mathrm{mL}^{-1}\right) \mathrm{e}$ o teor de proteína (mg.mL-1).

A separação por cromatografia de exclusão molecular se deu a partir do extrato bruto da amostra, o qual sofreu uma diluição. Retirou-se $2 \mathrm{~mL}$ do extrato e transferiu-se para uma balão volumétrico de $25 \mathrm{~mL}$ com solução tampão fosfato que melhor se desenvolveu na cinética. A coluna apresentou uma vazão de $20 \mathrm{~mL} \cdot \mathrm{H}^{-1}$. Frações de 2,0 $\mathrm{mL}$ foram coletadas em tubos de ensaio. Nestas frações foi realizado teste a fim de se verificar em quais frações se observava a atividade das enzimas peroxidase e polifenoloxidase e foram monitoradas as concentrações de proteínas por espectrofotometria no comprimento de onda de 280 nm.

Determinou-se também por meio do princípio de Linewever \& Burk (1934), a velocidade máxima (Vmáx) da reação enzimática e a constante de Michaelis-Menten $(\mathrm{Km})$, verificando a afinidade do guaiacol e do catecol com as enzimas peroxidase e polifenoloxidase, respectivamente. 


\section{Análises dos resultados}

Todas as análises foram feitas em triplicatas e o resultado expresso na forma de média e desvio padrão, com um intervalo de confiança de $98 \%$, utilizando o soft Statistica 7.0.

\section{RESULTADOS E DISCUSSÃO}

\section{Presença de fitonutrientes}

$\mathrm{Na}$ tabela 01 encontram-se os resultados dos fitonutrientes encontrados na polpa de bacaba.

Tabela 01 - Resultados dos fitonutrientes da polpa de bacaba paraense

\begin{tabular}{cc}
\hline Componentes Químicos & Situação \\
\hline Fenóis & Presente \\
Taninos & Ausente \\
Antocianinas e antocianidinas & Presente \\
Chalconas e auronas & Presente \\
Flavonas, flavonóis e xantonas & Presente \\
Leucoantocianidinas & Presente \\
Catequina (Taninos & Ausente \\
Catéquicos) & \\
Cumarinas & Ausente \\
Saponinas & Presente \\
Triterpenos pentaciclicos & Presente \\
Esteroides & Ausente \\
Alcaloides & Ausente \\
\hline
\end{tabular}

Contatou-se a presença de fenóis e vários tipos de flavonoides, esses grupos são responsáveis por apresentar inúmeras características, dentre elas a mais estudada é a capacidade antioxidante, a qual promove redução ou eliminação da ação dos radicais livres, compostos estes que são responsáveis por aumentarem o estresse oxidativo e podem danificar moléculas importantes, como proteínas, DNA dentre outros compostos (ALVES et al., 2013; IRONDI et al., 2015; SANTANGELO et al., 2016; CASAMENTI e STEFANI, 2017).

Ao analisar a tabela 01, observa-se a presença de alguns grupos de antocianinas presentes na polpa de bacaba. Ressalta-se que a presença de antocianinas nos alimentos é interessante já que algumas moléculas de antocianinas podem apresentar uma capacidade antioxidante maior quando comparadas com antioxidantes clássicos como butilato hidroxi anisol, butilato hidroxi tolueno e alfa tocoferol (vitamina E), além de que esses compostos propiciam a prevenção contra auto-oxidação e peroxidação de lipídeos em sistemas biológicos (GOUVÊA et al., 2012; KAKKAR \& BAIS, 2014).

Observou-se também a presença de triterpenóides pentaciclicos que proporcionam efeitos farmacológicos interessantes para o organismo humano, como, propriedades anti-inflamatórias, anticarcinogênica, antiviral, antibacteriana, antinociceptivo, gastroprotetora e hepatoprotetora, além de propriedades antimicrobianas citotóxicas e cardioprotetoras (BALTINA et al., 2003; KATERERE et al., 2003; OLIVEIRA et al., 2005; SILVA; DUARTE \& VIEIRA, 2014).

A polpa de bacaba apresentou também saponinas, que segundo a literatura estes compostos possibilitam ação expectorante e diurética, além de serem consideradas parte do sistemas de defesa, esta caracteristica é em virtudade da estrutura da molécula que apresenta um comportamento anfifílico que possibilidade gerar complexos com esteroides, proteínas e fosfolipídios das membranas, justificando as propriedades biológicas deste composto, já que algumas pesquisas observaram uma correlação entre o teor de saponinas com atividade antimicrobiana sobre o crescimento de fungos, além de inibir algumas bactérias como S. aureus, E. coli, E. faecalis, Klebsiella pneumoniae, Pseudomonas aeruginosa e Salmonella typhi (LOKESH; MANASVI \& LAKSHMI, 2016; SABOORA et al., 2019)

\section{Caracterização físico-química}

$\mathrm{Na}$ tabela 02 encontram-se os resultados das análises físico-químicas da polpa de bacaba paraense. 
Tabela 02 - Resultados da analise físico-química

\begin{tabular}{lc}
\hline \multicolumn{1}{c}{$\begin{array}{c}\text { Determinações na } \\
\text { polpa de Bacaba }\end{array}$} & Média \\
\hline Acidez em Ácido Cítrico (\%) & $0,065 \pm 0,002$ \\
Umidade (\%) & $83,30 \pm 0,35$ \\
Sólidos Totais (\%) & $16,70 \pm 0,35$ \\
Proteína (\%)* & $8,80 \pm 0,20$ \\
Gordura (\%)* & $60,40 \pm 1,70$ \\
Cinzas (\%)* & $0,77 \pm 0,01$ \\
Açúcares Totais (\%) & $0,68 \pm 0,02$ \\
Açúcares Redutores (\%) & $0,58 \pm 0,02$ \\
Açúcares Não Redutores (\%) & 0,11 \\
pH & $4,1 \pm 0,01$ \\
\hline
\end{tabular}

Legenda: *(resultados expressos em mateira seca)

Ao observar a tabela 02 , pode-se constatar que polpa de bacaba apresentou baixo teor de açucares redutores e altos teores de lipídeos. Quando comparado o teor de lipídeos com outras polpas, nota-se que a polpa de bacaba paraense é maior do que polpas de frutas analisadas por Canuto et al. (2010) Euterpe oleracea
(27,54\%), Oenocarpus bacaba (59,67\%), Ebling et al. (2016) Psidium guajava L. (0,33\%) e Andrade, Santos e Castle (2010) Spondias mombin L (2,45\%).

Constatou-se também que o teor de proteínas superou outras polpas como de Ebling et al. (2016) Psidium guajava L. (3,3\%) e Andrate, Santos e Castle (2010) Spondias mombin L (7,75\%).

Os teores destes compostos mostrados na tabela 02 podem variar entre diferentes localidades, em função de diversas variáveis como temperatura, intensidade de luz e conteúdo de umidade, além do processamento da polpa, que pode afetar bastante a concentração de nutrientes (STEFANOSKI et al., 2013).

\section{Análises de compostos bioativos}

Na tabela 03, encontram-se os resultados dos compostos bioativos.

Tabela 03 - Resultados dos compostos bioativos da polpa de bacaba paraense

\begin{tabular}{ccc}
\hline Determinações na polpa de Bacaba & Média* & Média** \\
\hline Compostos Fenólicos $\left(\mathrm{mg}^{*} 100 \mathrm{~g}^{-1}\right)$ & $98,0 \pm 0,45$ & $574,25 \pm 0,45$ \\
Flavonoides Totais $\left(\mathrm{mg} \cdot 100 \mathrm{~g}^{-1}\right)$ & $16,41 \pm 0,18$ & $96,53 \pm 0,18$
\end{tabular}

Legenda: *(resultados em matéria úmida) **(resultado em matéria seca)

Ao comparar o teor de compostos fenólicos da tabela 03 com a literatura, observa-se que o teor de compostos fenólicos da bacaba paraense é superior em relação às polpas de bacaba analisadas por Timoni et al. (2015) que apresentou uma variação de 8,18 a 11,2 mg.100 $\mathrm{g}^{-1}$. No entanto, a bacaba paraense apresentou baixo teor de fenólicos quando comparada com os resultados encontrados por Finco et al. (2012) de 1759,27 mg.100g-1 em base seca, contudo, a polpa paraense apresentou maiores teores de compostos fenólicos quando comparado com outras polpas de frutas como os resultados encontrados pelos autores Morais et al., (2011) ao analisar as polpas de bacuri (Platonia insignis Mart.), polpa de cajá (Spondias mombin L.) e polpa de tamarindo (Tamrindus indica L.) encontrando valores de 7,23 a 10,35 mg.100 $\mathrm{g}^{-1}, 6,62$ a 70,92 mg.100g-1 e 23,57 a 23,35 mg.100g-1 respectivamente.

Neste trabalho observou-se que a bacaba apresenta teor considerável tanto de flavonoides como fenólicos, estes compostos apresentam inúmeras alegações funcionais pois reduzem o risco de acidentes coronários, apresentam uma atividade antioxidante, anti-microbiana e ação anti-inflamatória. Boa parte desses benefícios gerados por essas substancias se da pela capacidade inibidora ou de retardamento das reações de diversas espécies oxidantes, como radicais hidroxil, peroxi dentre outros. (SANDHAR et al., 2011; SOUSA et al., 2015; ARENAS-CHAVES et al., 2018)

\section{Capacidade antioxidante}


Na tabela 04, encontram-se os resultados dos diferentes métodos de capacidade antioxidantes.

Tabela 04 - Capacidade antioxidante da polpa da bacaba por diferentes métodos

\begin{tabular}{cc}
\hline Capacidade Antioxidante & Média* $^{*}$ \\
\hline DPPH $\left(\mathrm{g} \cdot \mathrm{gDPPH}^{-1}\right)$ & $226,4 \pm 1,2$ \\
ABTs $\left(\mu \mathrm{mol}\right.$ trolox.g $\left.{ }^{-1}\right)$ & $85,31 \pm 0,03$ \\
FRAP $\left(\mu \mathrm{mol}\right.$ sulfato de ferro.g $\left.\mathrm{g}^{-1}\right)$ & $61,67 \pm 0,33$ \\
$C U P R A C\left(\mathrm{mg}^{-1} \mathrm{~g}^{-1}\right)$ & $65,87 \pm 0,63$ \\
\hline
\end{tabular}

Legenda: *(resultados expressos em matéria seca)

Pode-se observar que a bacaba paraense apresenta uma capacidade antioxidante maior do que as amostras analisadas por Finco et al. (2012), que obteve 601 grama de polpa por grama $\mathrm{DPPH}^{-1}$ e por Carvalho et al. (2016) ao estudar diferentes genótipos de bacaba, onde os resultado variaram de 3651 a 4524 grama de polpa por grama de $\mathrm{DPPH}^{-1}$, revelando o alto potencial da bacaba paraense.

Em relação a análise de ABTs, a polpa da bacaba paraense apresenta maior capacidade antioxidante, quando comparada com a pesquisa de Finco et al. (2012), ao analisar Oenocarpus bacaba encontrando valores de $57.9 \mu \mathrm{mol}$ trolox.g-1 ${ }^{-1}$ Ressaltase que a polpa de bacaba apresenta maior capacidade antioxidante quando comparada com outras polpas de frutas, pois com base nos dados de pesquisa de Rufino et al. (2010) que analisou 18 tipos de frutos, a bacaba paraense apresentou uma capacidade antioxidante maior que 7 frutos dos 18 frutos estudados por Rufino et al. (2010), dentre eles pode-se citar (açaî) Euterpe oleracea Mart e a carnaúba (Copernicia prunifera val) que obtiveram 64,5 $\mu \mathrm{mol}$ trolox.g-1 e 16,4 $\mu \mathrm{mol}$ trolox. $\mathrm{g}^{-1}$ respectivamente.

Os métodos de FRAP e CUPRAC também são utilizados para medir a capacidade antioxidante. No método FRAP (Ferric Reducing Antioxidant Power) o complexo férrico-tripiridiltriazina (Fe $\mathrm{FIII} \mathrm{TPZ})$ é reduzido ao complexo ferroso $\left(\mathrm{Fe}_{\mathrm{II}}-\mathrm{TPZ}\right)$, na presença de um antioxidante e em condições ácidas. O complexo formado por esta reação possui uma coloração azul intensa, com absorção máxima a 593nm. Enquanto, que o método por CUPRAC baseia-se inicialmente na formação de um complexo entre $\mathrm{Cu}^{2+}$ com os ligantes da neocuproine (2,9-dimetil-1,10-fenantrolina) na proporção de 2:1 ligante em relação ao metal, com isso, na presença de compostos com atividade antioxidante o íon complexado $\mathrm{Cu}^{2+}$ é reduzido a $\mathrm{Cu}+$, alterando a cor do complexo e possibilitando mensurar a capacidade antioxidante em uma amostra (HUANG; OU \& PRIOR, 2005; PRIOR; WU \& SCHAICH, 2005).

Diferentemente do CUPRAC e FRAP, o DPPH baseia se na presença de uma substancia antioxidante que irá doador elétrons para o átomo de nitrogênio desemparelhado do radical DPPH, resultando na intensidade de absorção que diminuirá, consequentemente, a solução do radical irá mudar de cor para amarelo. Enquanto, que o ABTs está baseado na possibilidade das substancias antioxidantes em capturar o cátion ABTS •+, desta forma, resultando em um decréscimo na absorbância que será lida junto com a mudança de coloração (PÉREZ-JIMÉNEZ \& SAURA- CALIXTO, 2006; SUCUPIRA et al., 2012). Com base nesses principios pode-se constatar que a polpa de bacaba paraense apresenta um potencial antioxidante, confirmado por diferentes métodos.

Vale ressaltar que a discrepância entre os valores encontrados pela atividade antioxidante neste trabalho é fruto das diferentes metodologias aplicadas, que consistem em diferentes mecanismos de reação, gerador de radical, meio reacional, período de reação e reações baseadas nos mecanismos dos próprios métodos fornecendo essa variação nos resultados, essa discrepância foi notada também por Müller, Fröhlich \&Böhm (2011) ao comparar as metodologias de antioxidantes. 
Destaca-se as pesquisas de Song et al. (2010), que observaram uma correlação positiva entre os compostos bioativos em relação atividade antioxidante, essa relação foi percebida também neste trabalho sendo a correlação de $\mathrm{r}^{2}$ 0,9905 dos compostos bioativos com o método de ABTs, $\mathrm{r}^{2}$ 0,9125 dos compostos bioativos com DPPH, $\mathrm{r}^{2}$ 0,9337 dos bioativos com o método FRAP e r $\mathrm{r}^{2}$ 0,9038 dos bioativos com o método CUPRAC. Outros autores observaram diferentes correlação ao comparar compostos bioativos e atividade antioxidante sendo as pesquisas de Kaur e Kapoor (2002) com r r $^{2}$.6578, e Almeida et al. (2008) com $r^{2}$ de 0,7142 , constataram um correlação positiva entre o teor de compostos bioativos e a capacidade antioxidante das matérias primas vegetais. Essa correlação mostra que os compostos bioativos influenciam na atividade antioxidante, porém não são os únicos responsáveis pela mesma, em virtude de existir outros fatores que influenciam na capacidade antioxidante.

\section{Atividade enzimática}

Ao avaliar a atividade enzimática, se observou que a concentração da solução tampão de fosfato que obteve melhor desempenho foi $100 \mathrm{mM}$ em relação a $50 \mathrm{mM}$, conseguindo uma maior atividade enzimática, além desse fato, ressalta-se que ao analisar as diferentes concentrações de substrato, conclui-se que a melhor concentração de catecol para a atuação das enzimas na bacaba foi de $50 \mathrm{mM}$, em relação a polifenoloxidase, enquanto que para peroxidase foi o guaiacol de $20 \mathrm{mM}$. A partir desses resultados foram realizados a atividade ótima da enzima em $\mathrm{pHs}$ e temperaturas variadas.

\section{Determinação do pH ótimo para as enzimas POD e PPO nos extratos de polpa de bacaba}

Nas figuras 01 e 02, observa-se o melhor $\mathrm{pH}$ da atuação da enzima POD e PPO no extrato de polpa de bacaba.

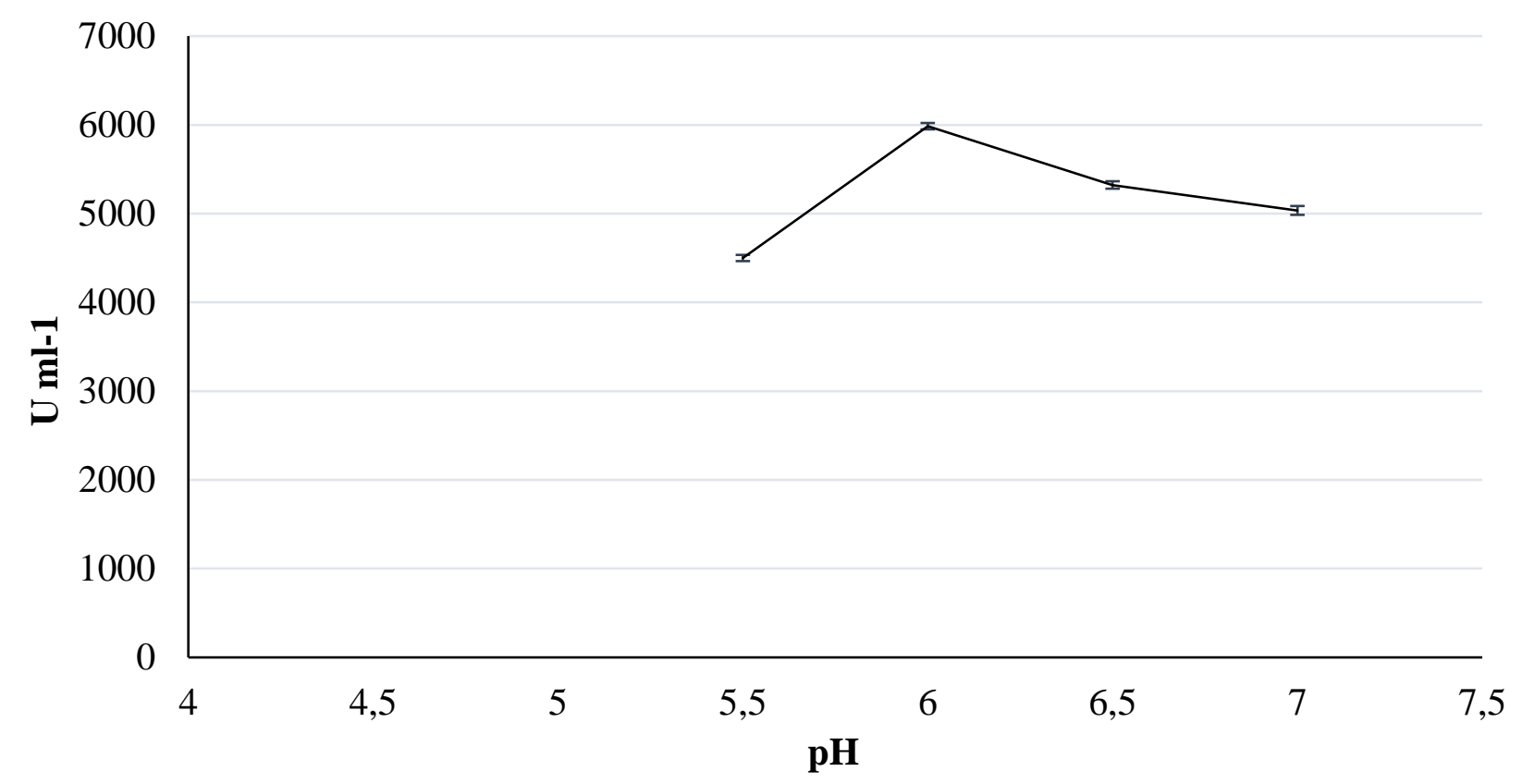

Figura 01. Comparação do pH durante a cinética enzimática do PPO 


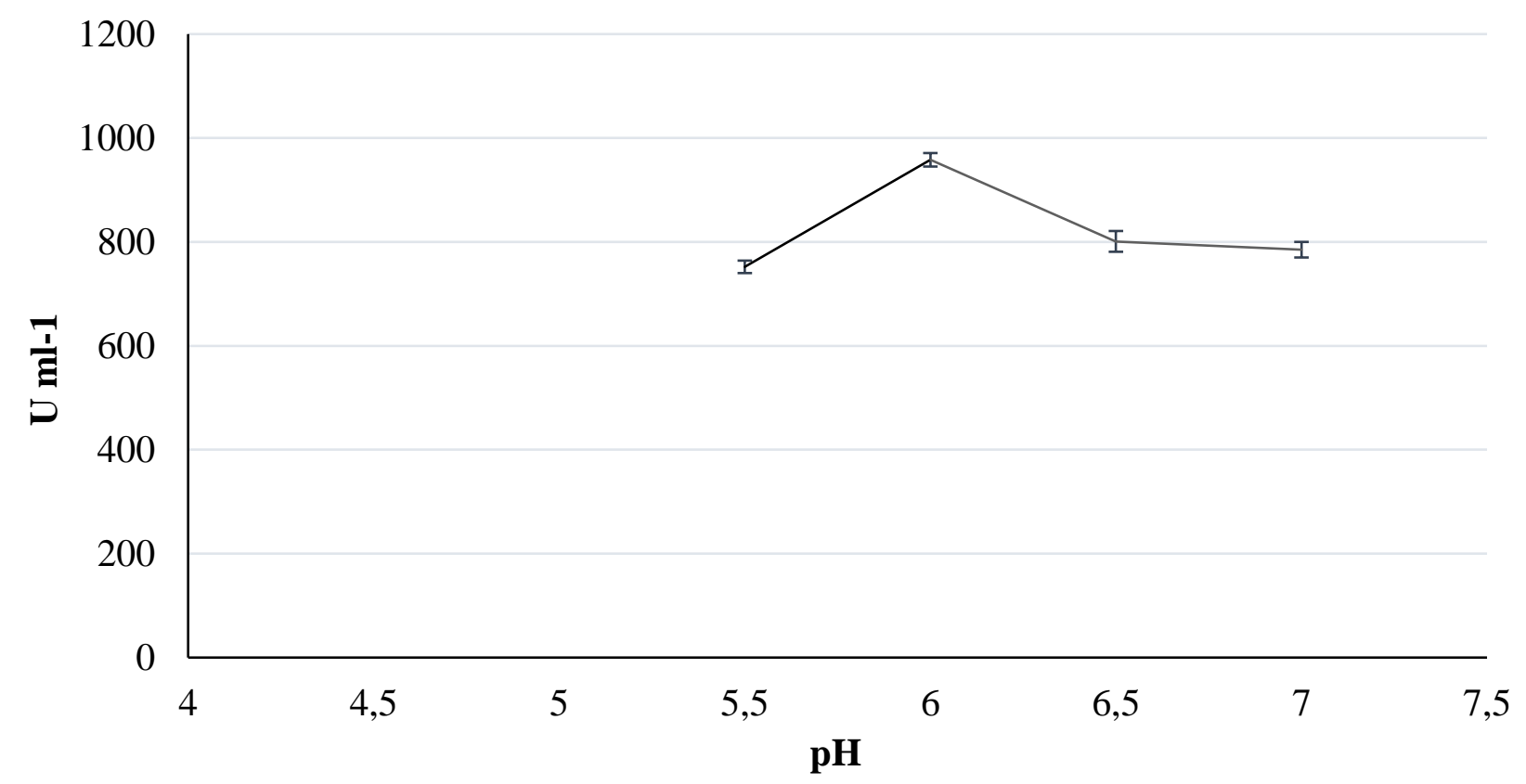

Figura 02. Comparação do pH durante a cinética enzimática da POD

Observou-se que tanto para POD quanto para PPO o pH 6,0 apresentou o meio propício para a maior atividade enzimática, porém segundo estudos de Evangelista (2006) ao analisar a atividade enzimática, observou que a PPO e POD podem apresentar conforme o alimento analisado uma variação na faixa ótima de $\mathrm{pH}$, fato verificado também por Halpin (1989), o qual observou que a gama de diferentes $\mathrm{pHs}$ é em virtude das isoenzimas presentes, fato que pode justificar a diferença entre os $\mathrm{pH}$ ótimos das enzimas em uma amostra.

\section{Determinação da temperatura ótima para as} enzimas POD e PPO nos extratos de polpa de bacaba.

As figuras 03 à 04 mostram o comportamento das diferentes temperaturas sobre as enzimas

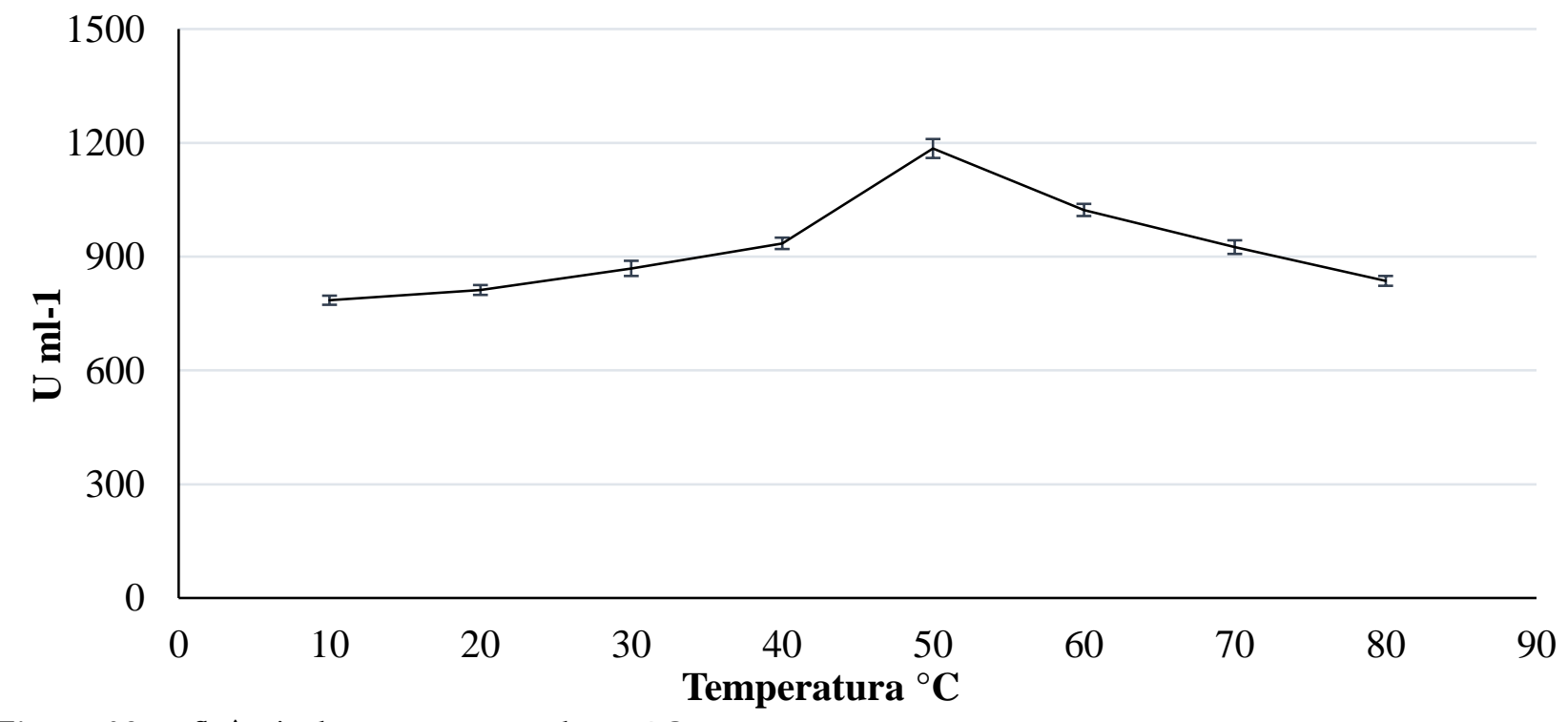

Figura 03. Influência da temperatura sobre a POD 


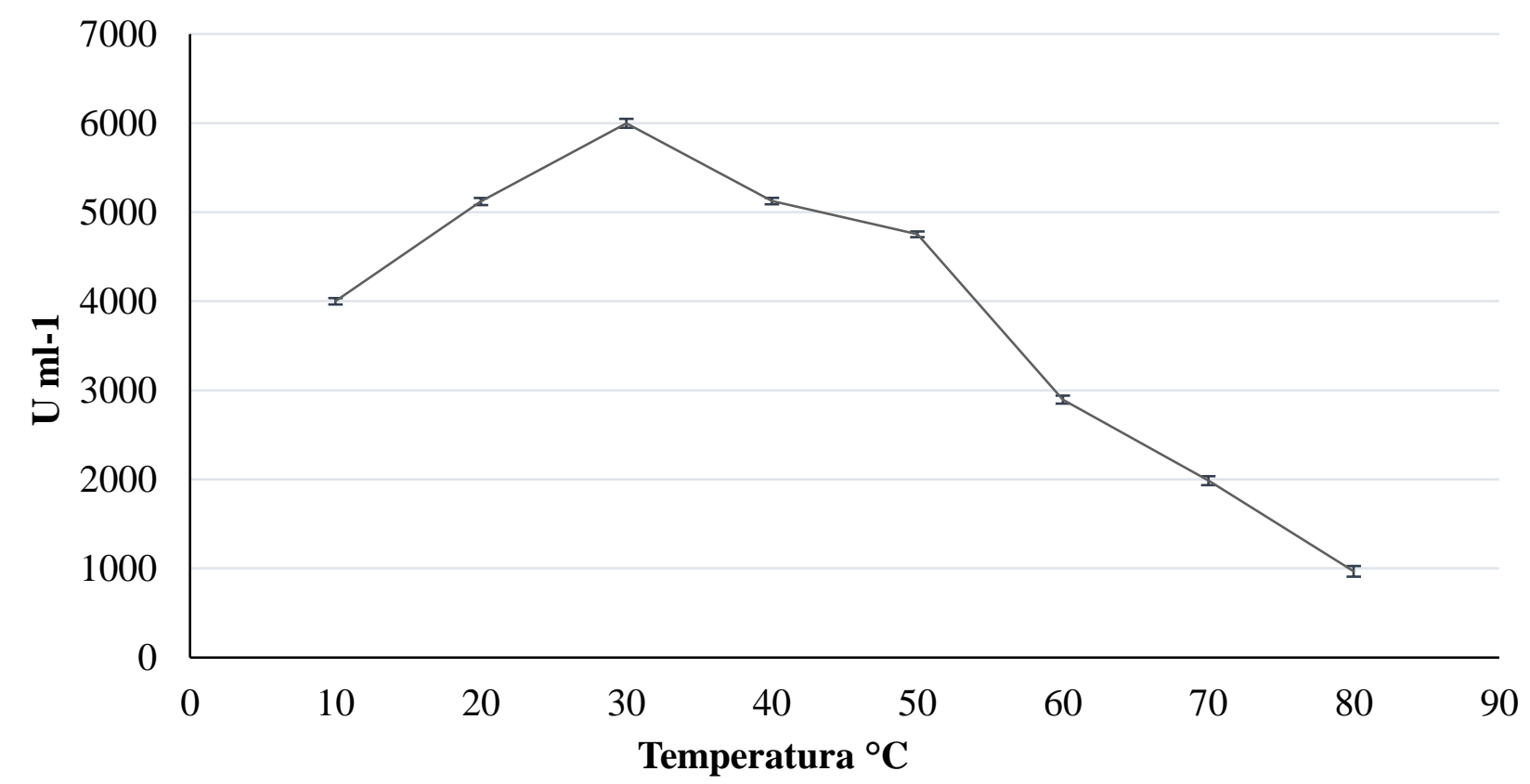

Figura 04. Influência da temperatura sobre a PPO

Segundo os autores Atkins e Jones (2006) comentam que nas reações químicas, a velocidade das reações enzimáticas aumenta com o aumento da temperatura, porém isto ocorre até que se atinja a velocidade máxima, a partir da qual começa a decrescer em virtude da estrutura tridimensional das enzimas se romperem, impossibilitando-a de formar o complexo enzima-substrato, fato que justifica o decaimento da atividade enzimática ao aumentar a temperatura, como mostrados nas figuras 03 e 04 .

No caso da polpa de bacaba, a atividade da PPO foi maior na temperatura de $30^{\circ} \mathrm{C}$, decaindo com o aumento da mesma, no entanto, no caso da POD foi à temperatura de $50^{\circ} \mathrm{C}$ que alcançou o melhor desempenho. Além da temperatura ótima, observou-se que PPO é mais sensível sendo bastante inibida à medida que aumenta a temperatura chegando a uma inibição de 97\% em relação à atividade ótima. Outros pesquisadores da enzima PPO já observaram comportamento semelhante como no caso de Galdino e Clemente (2008) que conseguiram a inativação de 70 a $80 \%$ da PPO nas amostras de pupunha, mostrando a sensibilidade da enzima com variação de temperatura de 65 a $85^{\circ} \mathrm{C}$ por 10 minutos, diferentemente da POD, a qual é mais termoestável.

Segundo Macedo et al. (2005) a POD, é uma enzima resistente a elevadas temperaturas e sua inativação tem sido frequentemente usada como índice de eficiência do branqueamento, tratamento térmico aplicado em alimentos para inibir a ação das enzimas. A perda da atividade enzimática da POD num produto branqueado indica uma perda correspondente da atividade das outras enzimas deteriorantes.

$\mathrm{Na}$ tabela 05 encontram-se a quantificação do teor de proteínas, atividade enzimática e especifica do extrato bruto da polpa de bacaba. 
Tabela 05. Quantificação do teor de proteínas, atividade enzimática e especifica do extrato bruto

\begin{tabular}{c|c|c|c|c|c}
\hline Amostra & $\begin{array}{c}\text { A.E.E.B. PPO } \\
\text { (U.mL }\end{array}$ & $\begin{array}{c}\text { A.E.E.B. POD } \\
\text { (U.mL }\end{array}$ & $\begin{array}{c}\text { A.E.E.E.B. } \\
\text { PPO } \\
\text { (U.mg }\end{array}$ & $\begin{array}{c}\text { A.E.E.E.B. POD } \\
\text { (U.mg-1) }\end{array}$ & $\begin{array}{c}\text { T.P.E.B. } \\
(\mathbf{m g . m L}\end{array}$ \\
\hline $\begin{array}{c}\text { Polpa da } \\
\text { Bacaba }\end{array}$ & $6000 \pm 35$ & $1274,66 \pm 15$ & $2985,07 \pm 1,5$ & $634,15 \pm 1,78$ & $2,01 \pm 0,56$ \\
\hline
\end{tabular}

Legenda: A.E.E.B. = Atividade enzimática do extrato bruto; A.E.E.E.B.= Atividade enzimática especifica do extrato bruto; TP.E.B.= Teor de proteína do extrato bruto.

Pode-se observar na tabela 05 que a bacaba apresenta alta atividade das enzimas POD e PPO, sendo um fator negativo já que essas enzimas são responsáveis pelo escurecimento enzimático, gerando reações de oxirredução que culminarão da degradação de nutrientes bem como na qualidade sensorial do

Purificação das enzimas através de cromatografia de exclusão molecular

$\mathrm{Na}$ figura 05 se apresenta a separação das enzimas por cromatografia de exclusão molecular do extrato da bacaba. produto.

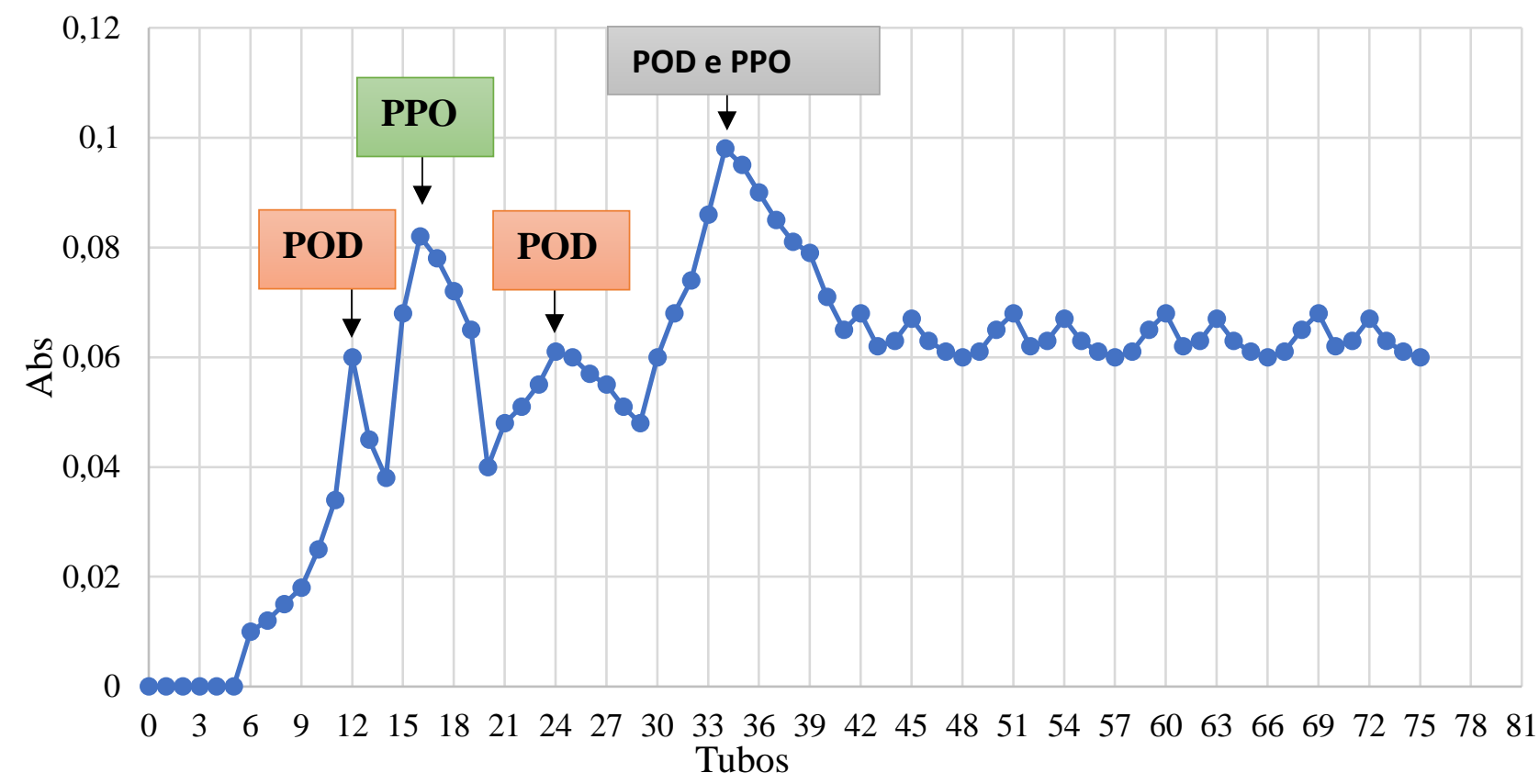

Figura 05. Cromatograma do fracionamento da peroxidase e polifenoloxidase na polpa de bacaba em gel sephadex g-50 $(2,5 \times 70 \mathrm{~cm})$ : volume das frações de 2,0 ml; monitoramento das proteínas (absorbância $280 \mathrm{~nm}$ )

Ao observa a figura 05 , constata-se que a cromatografia de exclusão molecular em gel Sephadex G-50 possibilitou a purificação parcial do extrato, tendo apresentado duas formas de PPO e três formas de POD. Ressalta-se que até o tubo 40 apresentou atividade enzimática, os demais tubos poderiam ser outros compostos como flavonoides, fenólicos e outras substâncias.
$\mathrm{Na}$ tabela 06 encontra-se a atividade enzimática e atividade especifica das enzimas PPO e POD purificadas na cromatografia por exclusão molecular em gel Sephadex G-50. 
Tabela 06 -Atividade enzimática do extrato parcialmente purificado

\begin{tabular}{|c|c|c|c|c|}
\hline Tubo & A.E.E.P. (U.mL $\left.\mathrm{mL}^{-1}\right)$ & A.E.E.E.P.(U.mg-1) & T.P.E.P.(mg.mL $\left.\mathrm{m}^{-1}\right)$ & $\begin{array}{c}\text { Fator de } \\
\text { purificação }\end{array}$ \\
\hline 11 (POD) & 256,25 & 711,805 & 0,36 & 1,12 \\
\hline 16 (PPO) & 990,0 & 3300 & 0,3 & 1,10 \\
\hline 24 (POD) & 722,5 & 2890 & 0,25 & 4,58 \\
\hline
\end{tabular}

Legenda: A.E.E.P. $=$ Atividade enzimática do extrato parcialmente purificado; A.E.E.E.P. $=$ Atividade enzimática especifica do extrato parcialmente purificado e T.P.E.P.= Teor de proteína do extrato parcialmente purificado

$\mathrm{Na}$ tabela 06 se observa os altos valores encontrados da atividade enzimática especifica em relação ao extrato bruto, resultado que foi possível graças a cromatografia por exclusão molecular, possibilitando a separação e concentração das diferentes formas de PPO e POD, além de constatar que o processamento de purificação alcançou um fator de purificação maior que 1 , mostrando que o processo de purificação aplicado não ofereceu perdas significativas da atividade enzimática.

Com base nessas informações, pode-se utilizar as enzimas purificadas que apresentaram uma alta atividade enzimática para outros processamentos tecnológicos, como, para fermentação do cacau ou cupuaçu para obtenção do chocolate, pois o período de fermentação e marcado por transformações bioquímicas efetuadas, principalmente, por enzimas que agregam as amêndoas características organolépticas desejáveis do chocolate, quando aplicadas no mosto fermentativo das sementes (FERREIRA, 2017).

$\mathrm{Na}$ tabela 07, encontram-se os valores de velocidade máxima de reação das enzimas polifenoloxidase e peroxidase e os valores da constante de Michaelis-Menten (Km).

Tabela 07- Resultados da Vmáx e Km das reações enzimáticas dos extratos parcialmente purificados.

\begin{tabular}{c|c|c}
\hline Amostra & Vmáx $\left(\mu \mathrm{M}^{\mathrm{min}}{ }^{-1}\right) \mathrm{POD}$ & Vmáx $\left(\mu \mathrm{M} \cdot \mathrm{min}^{-1}\right) \mathrm{PPO}$ \\
\hline \multirow{3}{*}{ Polpa da Bacaba } & $2,05 \times 10^{-04}$ & $1,73 \times 10^{-04}$ \\
\cline { 2 - 3 } & $\mathrm{Km} \operatorname{POD}(\mathrm{M})$ & $\mathrm{Km} \mathrm{PPO}(\mathrm{M})$ \\
\cline { 2 - 3 } & $6,70_{\mathrm{x}} 10^{-06}$ & $2,10_{\mathrm{x}} 10^{-05}$ \\
\hline
\end{tabular}

Em relação aos valores da constante de Michaelis-Menten $(\mathrm{Km})$ constatados na tabela 07, destaca-se a grande afinidade dos substratos fenólicos em relação às enzimas. Ademais, valores de $\mathrm{Km}$ são importantes, pois permitem calcular a concentração do substrato necessária para saturar todos os sítios ativos da enzima (ZERAIK; SOUZA \& FATIBELLO, 2008).

\section{CONCLUSÃO}

O estudo dos fitonutrientes qualitativo na polpa de bacaba indicou a presença dos compostos fenólicos, flavonoides, antocianinas, antocianidinas, chalconas, auronas, flavonas, flavonóis, xantonas, saponinas e terpenos, mostrando que a polpa paraense apresenta um grande potencial a ser explorado. A polpa de bacaba apresentou teor de fenólicos e flavonoides que foram expressivos, principalmente quando comparado com outras polpas.

A polpa da bacaba apresentou uma boa capacidade antioxidante mesurada pelos difenrentes métodos antioxidante (DPPH, CUPRAC, ABTS e FRAP). Estes resultados sugerem que a polpa da bacaba apresenta capacidade antioxidante com benefícios para 
o organismo já que apresentam compostos com princípios ativos de proteção.

Por fim, foi possível realizar a separação das enzimas PPO e POD através da cromatografia de exclusão molecular, além de que se constatou a alta atividade dessas enzimas bem como a grande afinidade dessas enzimas com os substratos fenólicos utilizados.

\section{REFERÊNCIAS}

Abadio Finco FDB, Böser S, Graeve, L. Antiproliferative activity of bacaba (Oenocarpus bacaba) and jenipapo (Genipina americana L.) phenolic extracts: A comparison of assays. Nutrition \& Food Science. 2013; 43(2): 98-106.

Abadio Finco FDB, Kammerer DR, Carle R, Tseng W H, Boser S, Graeve L. Antioxidant activity and characterization of phenolic compounds from bacaba (Oenocarpus bacaba Mart.) fruit by HPLC-DAD-MSn. Journal of Agricultural and Food Chemistry. 2012; 60(31), 7665-7673.

Abadio Finco FDB, Kloss L, Graeve L. Bacaba (Oenocarpus bacaba) phenolic extract induces apoptosis in the MCF-7 breast cancer cell line via the mitochondria-dependent pathway. Official Journal of the Society of Nutrition and Food Science. 2016; 5 (1): 5-15.

Ahn MR, Kumazawa S, Usui Y, Nakamura J, Matsuka M, Zhu F, Nakayama T. Antioxidant activity and constituents of propolis collected in various areas of China. Food Chemistry. 2007; 101 (1): 1388.

Almeida EM, Inês MSM, Lúcia VLAGL, Josefa RN. Capacidade antioxidante de frutas. Brazilian Journal of Pharmaceutical Sciences. 2008; 44 (2): 193- 201.

Alves MJ, Ferreira ICFR, Froufe HJC, Abreu RMV, Martins A, Pintado M. Antimicrobial activity of phenolic compounds identified in wild mushrooms, SAR analysis and docking studies. Journal of Applied Microbiology. 2013; 115 (2): 346-357.

Andrade RM, Santos AL, Castle HM. Caracterização física e físico-química dos frutos da cajazeira (Spondias mombin L.) e de suas polpas obtidas por dois tipos de extrator. Journal Food
Technology. 2010; 13 (2): 160- 163.

André GBC, Augusta AOX, Camargo LN, Toledo MB Caracterização físico-química de polpas de frutos da Amazônia e sua correlação com a atividade anti-radical livre. Revista Brasileira de Fruticultura. 2010; 32 (4): 1196-1205.

Apak R; Güçlü K; Özyürek M., Karademir SE Novel total antioxidant capacity index for dietary polyphenols and vitamins $\mathrm{C}$ and $\mathrm{E}$, using their cupric ion reducing capacity in the presence of neocuproine: CUPRAC Method. Journal of Agricultural and Food Chemistry. 2004; 52 (26): 7970-7981.

Arenas-Chavez CA, Wiche-Salinas T, ValenciaMercado I, Calle-Valdez R, Vera-Gonzales C, Malaga-Contreras S, Huanqui-Guerra C. Efecto antiiflamatorio de la fracción flavonoide de Lepechinia meyenii (Walp.) Epling (Salvia) sobre leucocitos de pacientes con artritis reumatoide. Revista Peruana de Medicina Experimental y Salud Pública. 2018; 35 (1): 55-61.

Association Of Official Analytical Chemists. Official Methods of analysis of AOAC International. Maryland: AOAC International, 2005. 3172 p.

Atkins PW, Jones L. Princípios de química: questionando a vida moderna e o meio ambiente. Bookman: Porto Alegre, 2006. 965p.

Baltina, LA, Flekhter OB, Nigmatullina LR, Boreko, EI, Pavlova NI, Nikolaeva SN, Savinova OV, Tolstikov GA. Lupane Triterpenes and Derivatives with Antiviral Activity. Bioorganic \& Medicinal Chemistry Letters. 2003; 13 (20): 3550.

Bradford MM. A rapid and sensitive method for the quantification of microgram quantities of protein-dye binding. Analytical Biochemistry. 1976; 72 (1-2): 248-254.

Brand-Willians W, Cuvelier ME, Berset C. Use of a free radical method to evaluate antioxidant activity. Food Science and Technology. 1995; 28 (1): 2830.

Canuto GAB, Xavier AAO, Neves LC, Benassi MDT. Caracterização físico-química de polpas de frutos da Amazônia e sua correlação com a atividade anti-radical livre. Revista Brasileira de Fruticultura. 2010; 32 (4): 1196-1205. 
Carneiro FT, Berni MD, Dorileo IL, Rostagno MA. A Biorefinerystudy of availability of agriculture residues and wastes for integrated biorefineries in Brazil. Resources, Conservation and Recycling. 2013; 77 (1) 78-88.

Carvalho AV, Silveira TF, Sousa SHB, Moraes MR, Godoy HT. Phenolic composition and antioxidant capacity of bacaba-de-leque (Oenocarpus distichus Mart.) genotypes. Journal of Food Composition and Analysis. 2016; 54 (1): $1-9$.

Casamenti F, Stefani M. Olive polyphenols: New promising agents to combat aging-associated neurodegeneration. Expert Review of Neurotherapeutics. 2017; 17 (4): 345-358.

Ebling PM, Lopes LD, Oliveira AF, Augusti AB, Linde MA, Maria SMB. Centesimal composition, bioactive compounds, antioxidant activity and phenolic characterization of guava pulp. Disciplinarum Scientia. 2016; 17 (2): 210-212.

Eiserhardt WL, Svenning JC, Kissling WD, Balslev H. Species Diversity and Growth Forms in Tropical American Palm Communities. The Botanical Review. 2011; 77 (1): 381-425.

Evangelista RM, Vieites RL. Avaliação da qualidade de polpa de goiaba congelada, comercializada na cidade de São Paulo. Segurança Alimentar e Nutricional. 2006; 13 (2): 76-81.

Fernandes SC, Oliveira IRWZ, Vieira IC. A green bean homogenate immobilized on chemically cross linkedchitin for determination caffeic acid in white wine. Enzyme and Microbial Technology. 2007; 40 (3): 661-668.

Ferreira ASF. Estudo bioquímico da fermentação da semente de cupuaçu (Theobroma grandiflorum Schum) e obtenção de um derivado de chocolate [dissertação]. Belém: Universidade do Estado do Pará; 2017.

Finco FDBA, Kammerer DR, Reinhold CR, Wen-Hsin TWH, BoSer S, Graeve L. Antioxidant activity and characterization of phenolic compounds from bacaba (Oenocarpus bacaba Mart.) fruit by HPLC-DAD-MS. Journal of Agricultural and Food Chemistry. 2012; 60 (8): 7665-7673.

Firuzi O, Lacanna A, Petrucci R, Marrosu G, Saso L. Evaluation of the antioxidant activity of flavonoids by "ferric reducing antioxidant power" assay and cyclic voltammetry. Biochimica Biophysica Acta. 2005; 1721 (1): 180 184.

Galdino NO, Clemete E. Palmito de pupunha (Bactris gasipaes Kunth.) composição mineral e cinética de enzimas oxidativas. Ciência e Tecnologia de Alimentos. 2008; 28 (3): 540544.

Georgé S, Brat P, Alter P, Amiot MJ. Rapid Determination of Polyphenols and Vitamin $C$ in Plant-Derived Products. Journal of Agricultural and Food Chemistry. 2005; 53 (1): 1370.

Gouvêa ACMS, Araujo MCP, Schulz DF, Pacheco S, Godoy RLO, Cabral LMC. Anthocyanins standards (cyanidin-3-O-glucoside and cyanidin3-O-rutinoside) isolation from freeze-dried açaí (Euterpe oleraceae Mart.) by HPLC. Food Science and Technology. 2012; 32 (1): 43-46.

Halpin P, Pressey R, Jen J, Mondy N. Purification and Characterization of Peroxidase Isoenzyme from Green Peas (Pisum sativum). Journal of Food Science. 1989; 54 (3) 644-649.

Huang D, Ou B, Prior RL. The chemistry behind antioxidant capacity assays. Journal of Agricultural and Food Chemistry. 2005; 53 (6): 1841-1856.

Instituto Adolf Lutz (São Paulo). Métodos físicoquímicos para análise de alimentos/ coordenadores Odair Zenebon, Neus Sadocco Pascuet e Paula Tigela - são Paulo: Instituto Adolf Lutz, 2008 p. 1020.

Irondi EA, Oboh G, Akindahunsi AA, Boligon AA, Athayde ML. Phenolics composition and antidiabetic property of Brachystegia eurycoma seed flour in high-fat diet, low-dose streptozotocininduced type 2 diabetes in rats. Asian Pacific Journal of Tropical Disease. 2015; 5 (1): 159-165.

Kakkar S, Bais S. A review on protocatechuic acid and its pharmacological potential. ISRN pharmacology. 2014; 14 (1): 01-09.

Katerere DR, Gray AI, Nash RJ, Waigh RD. Antimicrobial activity of pentacyclic triterpenes isolated from African Combretaceae. Phytochemistry. 2003; 63 (1): 76 -87.

Kaur C, Kapoor HC. Anti-oxidant activity and total 
phenolic content of some Asian vegetables. International Journal of Food Science \& Technology. 2002; 37 (2): 153-161.

Kuskoski EM, Asuero AG, García-Parilla MC, Troncoso AM, Fett R. Actividad antioxidante de pigmentos antocianicos. Ciência e Tecnologia de Alimentos. 2004; 24 (4) 691-693.

Leba LJ, Brunschwig C, Saout M, Martial K, Bereau D, Robinson JC. Oenocarpus bacaba and Oenocarpus bataua leaflets and roots: A new source of antioxidant compounds. International Journal of Molecular Sciences. 2016; 17(7), 1014.

Linewever H, Burk D. The determination of enzyme dissociation constants. Journal of American Chemical Society. 1934; 56 (1): 658-666.

Lokesh RAVI, Manasvi V, Lakshmi BP. Antibacterial and antioxidant activity of saponin from Abutilon indicum leaves. Asian Journal of Pharmaceutical and Clinical Research. 2016; 9 (3): 344-347.

Macedo GA, Pastore GM, Sato HH, Park YGK Bioquímica experimental de alimentos. São Paulo: Editora Varela; 2005. 187 p.

Maldonade IR, Amaya RD, Scamparini ARP. Carotenoids yeasts isolated from the Brazilian ecosystem. Food Chemistry. 2008; 107 (1): 145 150 .

Matos FJA. Introdução à Fitoquímica Experimental. Fortaleza: UFC edições; 1997. 62 p.

Meda A, Lamien CE, Romito M, Millogo J, Nacoulma OG.; Determination of the total phenolic, flavonoid and proline contents in Burkina Fasan honey, as well as their radical scavenging activity. Food Chemistry. 2005; 91 (1): 574.

Morais LV, Séfora MBS, Mancini JF, Lima A. Fenólicos totais e capacidade antioxidante in vitro de polpas de frutos tropicais. Revista Brasileira de Fruticultura. 2011; 33 (2): 893- 896.

Müller L, Fröhlich K, Böhm V. Comparative antioxidant activities of carotenoids measured by ferric reducing antioxidant power (FRAP), ABTS bleaching assay ( $\alpha$ TEAC), DPPH assay and peroxyl radical scavenging assay. Food Chemical. 2011; 129 (10):139-148.
Nascimento RAD, Andrade EL, Santana EB, Ribeiro NFDP, Costa CML, Faria LJGD. Bacaba powder produced in spouted bed: an alternative source of bioactive compounds and energy food product. Brazilian Journal of Food Technology. 2019; 22 (1): 1-15.

Neri-Numa IA, Soriano Sancho RA, Pereira APA, Pastore GM. Small Brazilian wild fruits: Nutrients, bioactive compounds, healthpromotion properties and commercial interest. Food Research International. 2018; 103 (1): 345 360 .

Neves LTBC, Campos DCDS, Mendes JKS, Urnhani CO, Araújo KG Qualidade de frutos processados artesanalmente de açaí (Euterpe oleracea Mart.) e bacaba (Oenocarpus bacaba Mart.). Revista Brasileira de Fruticultura. 2015; 37 (3) 729-738.

Oliveira FA, Chaves MH, Almeida FR, Lima RCJR, Silva RM, Maia JL. Protective effect of alphaand beta-amyrin, a triterpene mixture from Protium heptaphyllum (Aubl.) March. trunk wood resin, against acetaminophen-induced liver injury in mice. Ethnopharmacol. 2005; 98 (2): 103-105.

Pérez-Jiménez J, Saura-Calixto F. Effect of solvent and certain food constituents on different antioxidant capacity assays. Food Research International. 2006; 39 (1):791-800.

Prior RL, Wu X, Schaich K. Standardized Methods for the Determination of Antioxidant Capacity and Phenolics in Foods and Dietary Supplements. Journal of Agricultural and Food Chemistry. 2005; 53 (18): 4290-4302.

Rufino MDSM, Alves RE, Brito ES, Pérez-Jiménez J, Saura-Calixto F, Mancini-Filho J. Bioactive compounds and antioxidant capacities of 18 non-traditional tropical fruits from Brazil. Food chemistry. 2010; 121(4): 996-1002.

Saboora A, Sajjadi ST, Mohammadi P, Fallahi Z. Antibacterial activity of different composition of aglycone and glycosidic saponins from tuber of Cyclamen coum Miller. Industrial Crops and Products. 2019; 140 (1): 1662.

Sandhar HK, Kumar B, Prasher S, Tiwari P, Salhan M, Sharma P. A review of phytochemistry and pharmacology of flavonoids. Internationale pharmaceutica sciencia. 2011; 1 (1): 25-41. 
Santangelo C, Filesi C, Varì R, Scazzocchio B, Filardi T, Fogliano V, D'archivio M, Giovannini C, Lenzi A, Morano S. Consumption of extra-virgin olive oil rich in phenolic compounds improves metabolic control in patients with type 2 diabetes mellitus: a possible involvement of reduced levels of circulating visfatin. Journal of endocrinological investigation. 2016; 39 (11): 1295-1301.

Silva FC, Duarte LP, Vieira Filho SA. Celastráceas: Fontes de Triterpenos Pentacíclicos com Potencial Atividade Biológica. Revista Virtual Quimica. 2014; 6 (5): 1205-1220.

Singleton VL, Orthofer R, Lamuela-Raventós RM. Analysis of total phenols and other oxidation substrates and antioxidants by means of folinciocalteu reagent. Methods in enzymology. 1999; 299 (1):152-178.

Song W, Derito CM, Liu MK, He X, Dong M, Liu RH. Cellular antioxidant activity of common vegetables. Journal of Agricultural and Food Chemistry. 2010; 58 (11): 6621-6629.

Sousa JR, Farias MYV, Lemos, CMGF, Silva JA, Souza MCM, Gonçalves LRB. Avaliação da casca de Passiflora eduliscomo fonte de flavonoides. Blucher Chemical Engineering Proceedings. 2015; 1 (2): 556-563.
Stefanoski DC, Santos GG, Marchão RL, Petter FA, Pacheco LP. Uso e manejo do solo e seus impactos sobre a qualidade física. Revista brasileira de engenharia agrícola e ambiental. 2013; 17 (12): 1301-1309.

Sucupira NR, Silva AB, Pereira G, Costa JN. Métodos para determinação da atividade antioxidante de frutos. Journal of Health Sciences. 2012; 14(4): 263 269.

Ugochukwu SC, Uche A, Ifeanyi O. Preliminary phytochemical screening of different solvent extracts of stem bark and roots of Dennetia tripetala G. Baker. Asian Journal of Plant Science and Research. 2013; 3 (3): 10-13.

Vieira IC, Lupetti KO, Fatibello-Filho O. Determinação de paracetamol em produtos farmacêuticos usando um biossensor de pasta de carbono modificado com extrato bruto de abobrinha (Cucurbita pepo). Quimica Nova. 2003; 26 (1) 39-43.

Zeraik AE, Souza FSAD, Fatibello-Filho O, Leite OD. Desenvolvimento de um spot test para o monitoramento da atividade da peroxidase em um procedimento de purificação. Química Nova. 2008; 31 (4): 731-734. 